\title{
A pele da tilápia no tratamento de queimaduras de segundo e terceiro graus, além de mais eficiente, é de baixíssimo custo
}

\section{The skin of tilapia in the treatment of burns of second and third degrees beyond more efficient, is low cost}

\author{
Cristhian Enmanuel Ayala Gimenez' $\bullet$ Amanda Guimaraes Camargo Bianco² $\bullet$ Eduardo Severo Monteiro $^{3}$ \\ Ariela Mosmann Ribas ${ }^{4} \bullet$ Eloisa Christini Beutler ${ }^{5} \bullet$ Maicon Balduíno Mazzo ${ }^{6}$ \\ Francisco Deleon Oliveira dos Santos ${ }^{7} \bullet$ Fabio Setti Ximenes $^{8} \bullet$ Fernanda Waitman de Oliveira Silva $^{9}$ \\ Elissandra Nascimento da Costa ${ }^{10} \bullet$ Matheus Zahr Geronimo" • Elenice Pedroso da Silva ${ }^{12}$ \\ Chayenne Gomes Bueno Arantes ${ }^{13} \bullet$ Lays Alexandre Bezerra ${ }^{14}$
}

O intuito desta pesquisa é demonstrar que já é possível o tratamento de queimaduras de uma forma que venha diminuir o sofrimento do paciente. É sabido que os ferimentos em decorrência de queimaduras são, por sua natureza, extremamente doloridos, sobretudo, no momento da troca do curativo.

As queimaduras constituem um grave problema de saúde pública, representando a segunda causa de morte na infância no Brasil. Segundo a Sociedade Brasileira de Queimaduras, estima-se que, no Brasil, ocorram em torno de um milhão de acidentes com queimaduras por ano. Destes, cem mil pacientes procuram atendimento hospitalar e cerca de dois mil e quinhentos falecerão, direta ou indiretamente, de suas lesões.

Diante desta situação, o professor/coordenador do SOS Queimaduras e Feridas do Hospital São Marcos de Recife (PE) conjuntamente com a equipe de pesquisadores liderados pelo professor Edmar Maciel, presidente do Instituto de Apoio ao Queimado (IAQ), propuseram que o tratamento de feridas oriundas de queimaduras com a pele da tilápia tem se revelado muito eficaz, principalmente, por evitar as dores que ocorrem no momento da troca do curativo.

Informa ainda que além da eficiência na cura dos ferimentos, este tratamento não submete o paciente às fortes dores e incômodo no momento da troca do curativo, uma vez que, por meio deste procedimento, não há necessidade da troca do curativo.Além de não haver necessidade da troca do curativo, que já seria muito importante, em razão de evitar o paciente do sofrimento, também revelou-se que a pele do pescado possui duas vezes mais colágenos (tipo I) que a pele humana.

No ano de 2017, a equipe dos pesquisadores realizou teste com 60 pacientes e os resultados obtidos foram altamente positivos

'Fisioterapeuta pela Universidad Internacional Tres Fronteras, Paraguay. Postgraduado en Didáctica Universitaria - Universidad La Paz- Paraguay. Graduado en medicina - Universidad Internacional Tres fronteras - Paraguay. Curso de Postgraduacion en salud pública y administración hospitalaria- Universidad del SolParaguay. Curso de la maestría en ciencias de la educación- Universidad del sol - Paraguay E-mail: cristhiancde_aya@hotmail.com.

${ }^{2}$ Acadêmico de Medicina pela Universidad Politécnica y Artística del Paraguay. E-mail:Amandacamargob@outlook.com.Autor correspondente.

${ }^{3}$ Acadêmico de Medicina pela Universidad Politécnica y Artística del Paraguay.E-mail: Eduardo_jp@hotmail.com.

${ }^{4}$ Acadêmico de Medicina pela Universidad Politécnica y Artística del Paraguay. E-mail:Arielamosmannr@gmail.com.

${ }^{5}$ Acadêmico de Medicina pela Universidad Politécnica y Artística del Paraguay. E-mail: eloisabeutler@hotmail.com.

${ }^{6}$ Acadêmico de Medicina pela Universidad Politécnica y Artística del Paraguay. E-mail: Maiconmazzo@hotmail.com.br.

${ }^{7}$ Fisioterapeuta pelo Instituto de Ensino Superior de Alagoas. Acadêmico de Medicina pela Universidad Politécnica y Artística del Paraguay. E-mail: Deleon.del@ gmail.com.

${ }^{8}$ Acadêmico de Medicina pela Universidad Politécnica y Artística del Paraguay. E-mail: Fabio_sp_99@hotmail.com.

${ }^{9}$ Farmacêutica pela Universidade Braz Cubas. Iniciação científica em farmacologia pela Universidade Federal de São Paulo (UNIFESP). Mestre em Biotecnociência pela Universidade Federal do ABC (UFABC).Acadêmico de Medicina pela Universidad Politécnica y Artística del Paraguay. E-mail: fewaitman@hotmail.com.

${ }^{10}$ Enfermeira pela Universidade FINCA.Acadêmico de Medicina pela Universidad Politécnica y Artística del Paraguay. E-mail: Maninhapvh@hotmail.com.

"Acadêmico de Medicina pela Universidad Politécnica y Artística del Paraguay. E-mail: Matheus.zg@hotmail.com.

${ }^{12}$ Enfermeira pela Universidade Unip. Pós-graduada em Auditoria e Gestão em Saúde e em Saúde Estética. Acadêmico de Medicina pela Universidad Politécnica y Artística del Paraguay. E-mail: elenicepedrosoda@gmail.com.

${ }^{13}$ Acadêmico de Medicina pela Universidad Politécnica y Artística del Paraguay. E-mail: chayennegbueno@gmail.com.

${ }^{14}$ Bacharel em Direito pela Faculdade Reinaldo Ramos.Acadêmico de Medicina pela Universidad Politécnica y Artística del Paraguay. E-mail: laysalexandre__@ hotmail.com. 
O estudo revelou que além do alívio da dor do paciente e maior eficácia da nova técnica, o custo do tratamento fica muito mais barato, porque o tratamento convencional é feito com pomada e há necessidade da troca do curativo a cada dois ou três dias, dependendo da gravidade dos ferimentos.

Com todos os benefícios e adaptação da pele da tilápia com a pele humana, não há necessidade de refazer o curativo como no tratamento convencional. Informam ainda que a pesquisa já revelou que o a nova técnica tem reduzido as dores em 30 a $50 \%$, o que é de muita significância para a qualidade do tratamento.

Além de todos os benefícios já relatados, convém destacar que o Brasil hoje figura entre os maiores produtores de peixes do mundo, e a tilápia representa $58,4 \%$ dessa produção, ou seja, mais de 280 mil toneladas. Convém destacar que $99 \%$ da pele da tilápia é descartado, o que significa dizer que a matéria prima é abundante e, por consequência, barata. São números muito expressivos e, lamentavelmente, está sendo desperdiçado algo muito importante para a Medicina, produto revolucionário para pacientes com queimaduras de segundo e terceiro grau.

De acordo com o Doutor Edmar Maciel, a ideia da utilização da pele da tilápia em queimados surgiu há cinco anos e hoje a pesquisa em torno da aplicação tem dois anos e meio. A pesquisa envolveu o trabalho de 49 profissionais da Universidade Federal do Ceará, sob a coordenação do Dr. Odorico Moraes.

O modo de preparação se processa com a retirada das peles das tilápias que depois são lavadas com água corrente e colocadas em caixas isotérmicas para serem enviadas para armazenamento no banco de peles da Universidade Federal do Ceará, que depois de passarem pela esterilização inicial, são enviadas para São Paulo, ao Instituto de Pesquisas Energéticas e Nucleares (IPEN) da Universidade de São Paulo (USP), onde passam por uma radioesterilização, (procedimento que elimina possíveis vírus e garante a segurança do produto). Quando voltam para o banco de peles, após cerca de 20 dias, as peles são refrigeradas, e podem ser utilizadas em até dois anos.

De acordo com a Organização Mundial de Saúde (OMS), recomenda-se um banco de pele para cada município com mais de 500.000 habitantes, mas a realidade no Brasil é outra, pois atualmente existem quatro unidades: São Paulo, Porto Alegre, Curitiba e Recife. Desses, existem somente três que estão ativos, quais sejam, São Paulo, Porto Alegre e Curitiba. Como a porcentagem de queimaduras são alarmantes, esses três bancos de peles conseguem suprir somente $1 \%$ da necessidade demandada no país.

A falta de informação, ou mesmo, um trabalho eficiente de publicidade, por parte das autoridades de saúde, tem causado um rendimento muito baixo de doações de peles. Entretanto, é possível que com um trabalho de divulgação eficiente da importância desse material, que é jogado fora pelos produtores, se possa aproveitar para a Medicina, de forma a suprir a demanda e evitar muito sofrimento humano.

O mais importante desta nova tecnologia de saúde é que temos no país matéria prima abundante e de baixíssimo custo que, com certeza, suprirá toda nossa demanda e, possivelmente, se revelará um produto com alto valor agregado para a exportação. 